\title{
THE IMPACT OF VARYING STATUTORY ARRANGEMENTS ON SPATIAL DATA SHARING AND ACCESS IN REGIONAL NRM BODIES
}

\author{
D. R. Paudyal ${ }^{\text {ab, }}$, K. McDougall ${ }^{\text {ac }}$, A. Apan ${ }^{\text {ad }}$ \\ ${ }^{a}$ School Civil Engineering and Surveying, Faculty of Health, Engineering and Sciences \\ University of Southern Queensland \\ Toowoomba, Queensland-4350, Australia \\ bpaudyal@usq.edu.au \\ ckevin.mcdougall@usq.edu.au \\ darmando.apan@usq.edu.au \\ Commission IV, WG IV/4
}

\begin{abstract}
KEY WORDS: Catchment Management, Natural Resource Management, Spatial Information, Spatial Data Infrastructure (SDI), Statutory Arrangement
\end{abstract}

\begin{abstract}
:
Spatial information plays an important role in many social, environmental and economic decisions and increasingly acknowledged as a national resource essential for wider societal and environmental benefits. Natural Resource Management is one area where spatial information can be used for improved planning and decision making processes. In Australia, state government organisations are the custodians of spatial information necessary for natural resource management and regional NRM bodies are responsible to regional delivery of NRM activities. The access and sharing of spatial information between government agencies and regional NRM bodies is therefore as an important issue for improving natural resource management outcomes. The aim of this paper is to evaluate the current status of spatial information access, sharing and use with varying statutory arrangements and its impacts on spatial data infrastructure (SDI) development in catchment management sector in Australia. Further, it critically examined whether any trends and significant variations exist due to different institutional arrangements (statutory versus non-statutory) or not. A survey method was used to collect primary data from 56 regional natural resource management (NRM) bodies responsible for catchment management in Australia. Descriptive statistics method was used to show the similarities and differences between statutory and non-statutory arrangements. The key factors which influence sharing and access to spatial information are also explored. The results show the current statutory and administrative arrangements and regional focus for natural resource management is reasonable from a spatial information management perspective and provides an opportunity for building SDI at the catchment scale. However, effective institutional arrangements should align catchment SDI development activities with sub-national and national SDI development activities to address catchment management issues. We found minor differences in spatial information access, use and sharing due to varying institutional environment (statutory versus non-statutory). The non-statutory group appears to be more flexible and selfsufficient whilst statutory regional NRM bodies may lack flexibility in their spatial information management practices. We found spatial information access, use and sharing has significant impacts on spatial data infrastructure development in catchment management sector in Australia.
\end{abstract}

\section{INTRODUCTION}

Australia, like many developed countries, utilises a catchmentbased approach for the management of natural resources including land and water (Commonwealth of Australia 2000).The current approach to catchment management relies upon the cooperation of the three tiers of government and community. The Commonwealth Government provides the policy and financial support and fosters the catchment management strategies by participation in the strategy formulation process. It is also responsible for ensuring Australia meets its international obligations in relation to the environment and the sustainable management of natural resources (Commonwealth of Australia 2000). State governments and two territory governments establish policies, institutional arrangements and the necessary legislation to facilitate the sustainable catchment management (Pannell, Ridley et al. 2008) and provide financial support to regional natural resource management NRM bodies and other community groups such as land care groups, indigenous communities and farm/water improvement groups to achieve ecologically sustainable catchment outcomes. The local government fosters community awareness and the formation of catchment care groups. It promotes the development of catchment management strategies and implements them with respect to the relevant parts of local authority plans and procedures (Paudyal, McDougall et al. 2011)

Regional delivery of natural resource management in Australia is founded on a policy framework of investment through the agreements between Commonwealth and state or territory governments (Davidson, Lockwood et al. 2007). The regionalisation of NRM in Australia has taken place in the context of a much broader interest in regional governance across a range of policy sectors (Morrison 2007). A regional approach to the Australian Government's NRM program was formalised under two national programs: the Natural Heritage Trust (NHT) Phase-II and the National Action Plan for Salinity and Water Quality (NAP). As part of the NHTII/NAP programs, National Resource Management (NRM) regions (56 in all) were established through bilateral agreements between the Commonwealth and state and territory governments (HC Coombs Policy Forum 2011). There are 56 regional NRM bodies which are responsible for catchment management in Australia. The regional NRM bodies are different in their name, corporate structure, catchment management philosophy, regional characteristics and relationship to the state government organisation. The variations occur within and between 
jurisdictions (HC Coombs Policy Forum 2011). However, the regional NRM bodies can be broadly categorised as either statutory or non-statutory in terms of their responsibilities.

Those regional NRM bodies which are established by state government have statutory responsibilities (Ryan, Broderick et al. 2010). The statutory regional NRM bodies are controlled by State Government for catchment management decision making. Those which are governed by members of the community are non-statutory. The non-statutory nature of arrangement means the regional NRM bodies are not perceived by communities as part of the state or Australian governments (Department of Environment and Resource Management 2011). In nonstatutory regional NRM bodies, there is a high level of volunteerism and are autonomous for regional decision making. The regional NRM bodies of New South Wales, Victoria, South Australia and Australian Capital Territory are statutory (defined by legislation) whilst the regional NRM bodies in Queensland, Western Australia, Tasmania and Northern Territory are nonstatutory. Amongst the 56 regional NRM bodies in Australia, 24 are statutory and the remaining 32 are non-statutory. At present, there is no evidence that community-based regional or statutory NRM bodies deliver better natural resource management outcomes (Griffith 2009). There have been done little research to assess and explore the impact of varying statutory arrangements for spatial information management and better catchment outcomes.

Spatial information plays an important role in many social, environmental and economic decisions and increasingly acknowledged as a national resource essential for wider societal benefits (Paudyal, McDougall et al. 2012). Natural Resource Management is one area where spatial information can be used for improved planning and decision making processes. The access and sharing of spatial information between government agencies and regional NRM bodies is therefore as an important issue for improving catchment management outcomes. The institutional and jurisdictional environment of regional NRM bodies could have an effect for the access, use and sharing of spatial information and eventually for better catchment management outcomes.

The aim of this study is to explore whether any trends or significant variations exist due to statutory or non-statutory arrangements. This paper emerged from a broader research agenda that whether community-based regional NRM bodies have easy access and better sharing and utilisation of spatial information or not. This paper has been organised into four sections. The first section of the paper provides a brief introduction to catchment management and NRM portals by Australian Jurisdiction. The second section describes the study area and research methods. A survey method has been used to collect primary data from 56 regional NRM bodies which are responsible for catchment management in Australia. The third section discusses the similarities and differences between statutory and non-statutory arrangements for spatial information access, use and sharing. The third section summarises the findings and the policy implications of this findings in the NRM sector in Australia.

\section{STUDY AREA AND METHODS}

The study area for this research is 56 regional NRM bodies of Australia. As illustrated in Figure 1, there are 14 regional NRM bodies in Queensland (QLD), 13 in New South Wales (NSW), eight in Victoria (VIC), eight in South Australia (SA), six in Western Australia (WA), three in Tasmania (TAS), one in the Australian Capital Territory (ACT) and one is in Northern Territory (NT). The regional NRM bodies in New South Wales, Victoria, South Australia and Australian Capital Territory are statutory (defined by legislation) whilst the regional NRM bodies in Queensland, Western Australia, Tasmania and Northern Territory are non-statutory. Amongst the 56 regional NRM bodies, 22 are statutory and the remaining 34 are nonstatutory. The main purpose of this comparison is to explore whether any trends and significant variations exist due to statutory arrangements.

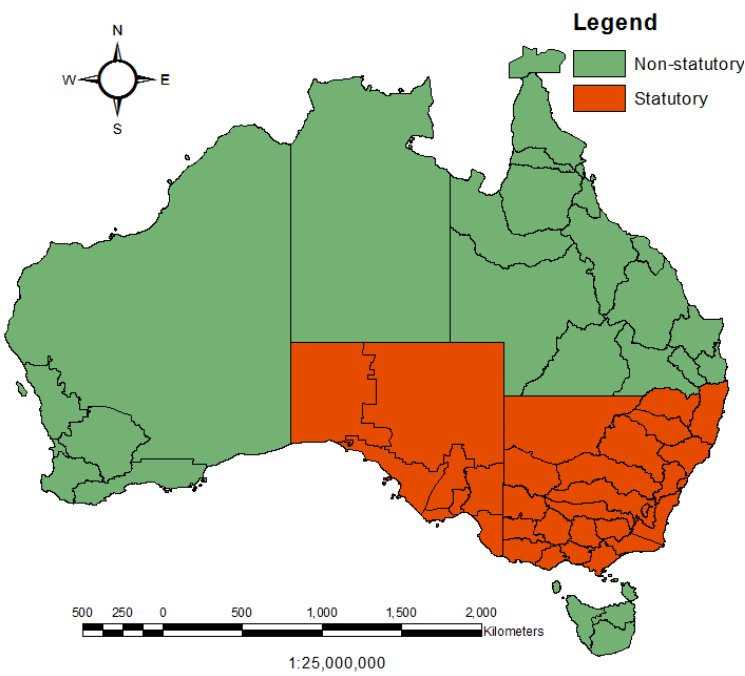

Figure 1. Study area

A total of 56 valid responses were received to the on-line questionnaire giving an overall response rate of $100 \%$. The questionnaire survey was undertaken between June 2010 and September 2010. The questionnaire survey was distributed in two stages. Initially, the questionaries were distributed to regional NRM bodies which belong to the Murray Darling Basin Authority (MDBA) and later to the remaining NRM bodies around Australia. The feedback and experience from the first distribution assisted in the second stage of the survey and assisted in achieving the high response rate. The largest group of respondents was identified as Geographical Information System (GIS) officers, while other respondents were the staff who were directly or indirectly involved with spatial information management or the GIS operations of that regional NRM body. The responses were provided from their organisational point of view. The majority of the respondents were full-time staff. The profile of respondents has been illustrated in Figure 2. 


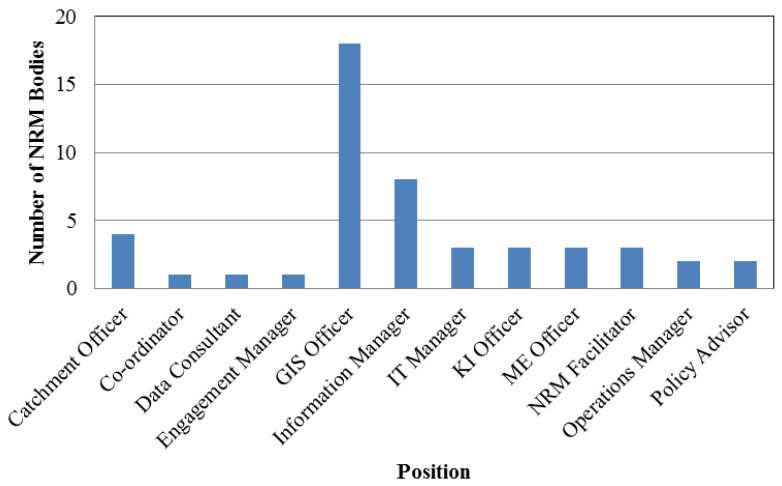

Figure 2. Profile of respondents (by position)

The support of regional NRM bodies was critical. The targeted respondent in each of the regional NRM bodies was identified and a contact e-mail address was collected through e-mail communication, telephone, and website/yellow pages. After identifying the respondent in each of the regional NRM body, a supporting e-mail with brief background about the research work and the survey link was sent through the principal supervisor. More than 40 per cent of responses were returned in the two week period after the e-mail was sent. A follow-up email was sent after three weeks and five weeks and a diary was maintained.

The online questionnaire was designed such that the data from the questionnaires was automatically collected into an Excel spreadsheet via the web server. This eliminated the possibility of errors in coding and transcription and accelerated transferring data into the data analysis software. A notification was obtained via e-mail when the online survey was submitted by the respondent. This enabled us to administer and collect the survey responses. For quality control purposes, the raw data were reviewed and cleaned before inputting into the statistical software. The statistical analysis of the survey results was undertaken in the SPSS statistical package.

A total of 36 questions were asked and organised into three areas; spatial information access, use and sharing. The spatial information access among regional NRM bodies in Australian States was assessed using variables such as the ease of access, restriction, impact of restriction, affordability of current pricing and spatial information access medium. The spatial information use among regional NRM bodies was assessed using variables such as the type of organisation, spatial information used by staff, GIS maturity and GIS activities and spatial information receiving medium. The spatial information sharing were assessed with various variables including collaborative arrangement, networking, use of open source models and social media, spatial policy, funding sources, importance of spatial data provider, spatial information integration issues and data sharing agreement arrangement.

\section{RESULTS}

In this section, the similarities and differences that exist between statutory (established by the state government) and non-statutory (community based) regional NRM bodies in spatial information access, use, and sharing for catchment management activities are discussed.

\subsection{Spatial Information Access}

With respect to accessing spatial data, there were no significant differences between statutory and non-statutory regional NRM bodies, although some variations were noted. Only $17 \%$ of non-statutory NRM bodies indicated that it was difficult to access spatial information whilst $28 \%$ of statutory NRM bodies indicated difficulty in accessing spatial information from spatial data providers (Figure3).

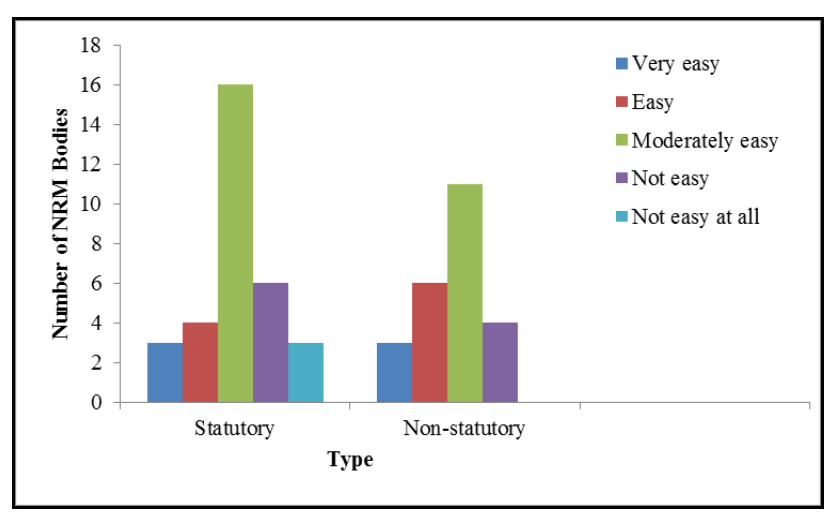

Figure 3. Ease of data access from spatial data provider

Approximately $42 \%$ of non-statutory and $28 \%$ of statutory regional NRM bodies advised that restrictions were placed (by the spatial data providers) on the use of spatial information, however, these did not limit their ability to undertake GIS activities. With respect to current pricing of spatial data, the non-statutory NRM bodies were more satisfied than statutory NRM bodies. This finding is interesting given that statutory NRM bodies are usually considered to be closely aligned with the state government. The most accepted pricing arrangement for the statutory group was the cost of transferring data, and for non-statutory group, it was free access. However, both groups agreed that the pricing depends upon the data type, and that foundation data should be free. This indicates that statutory bodies operate in a similar way to government organisations.

\subsection{Spatial Information Use}

The majority (92\%) of non-statutory organisations advised that they also supply spatial information and identified themselves as both spatial information providers and users. The number of statutory organisations that supply spatial information is relatively low (69\%) in comparison with the non-statutory group. This indicates that non-statutory organisations are more dynamic and proficient in spatial information management.

With respect to the use of spatial information by regional NRM staff, $40-60 \%$ of staff in both of the groups used spatial information for catchment management activities. Approximately half (48\%) of the regional NRM bodies in both of the groups identified themselves as mature GIS organisations using spatial information for 5-10 years or more. There are some variations regarding the mode of undertaking GIS activities. Ten out of 24 non-statutory organisations advised that they were undertaking GIS activities completely in-house. However, only two out of 36 statutory organisations advised that they were undertaking GIS activities completely in-house (Figure4). This indicates that statutory organisations are more dependent on other organisations, especially state government organisations and have perhaps less resources to undertake inhouse GIS activities. In contrast, non-statutory organisations 
appear to be more flexible and self-sufficient in undertaking GIS activities.

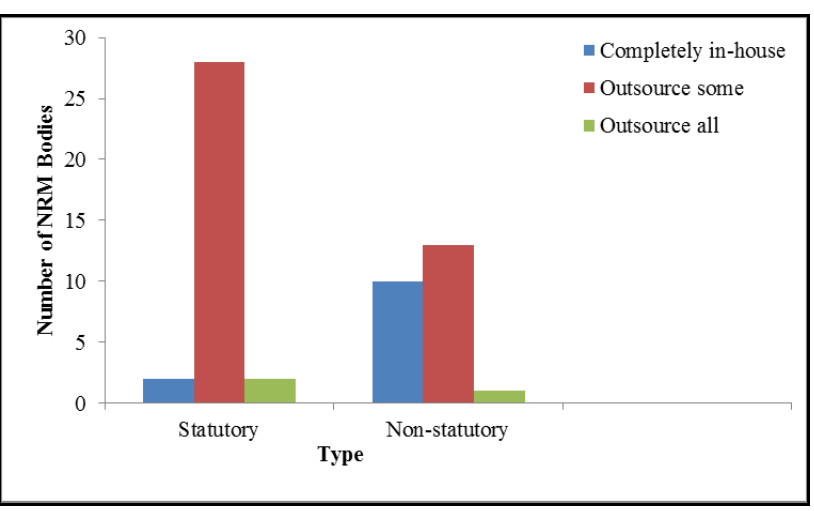

Figure 4: Mode of undertaking GIS activities

\subsection{Spatial Information Sharing:}

Almost $84 \%$ of the regional NRM bodies in both statutory and non-statutory groups indicated that they have some form of collaboration or networking activities with other organisations for spatial information management (Figure 5).

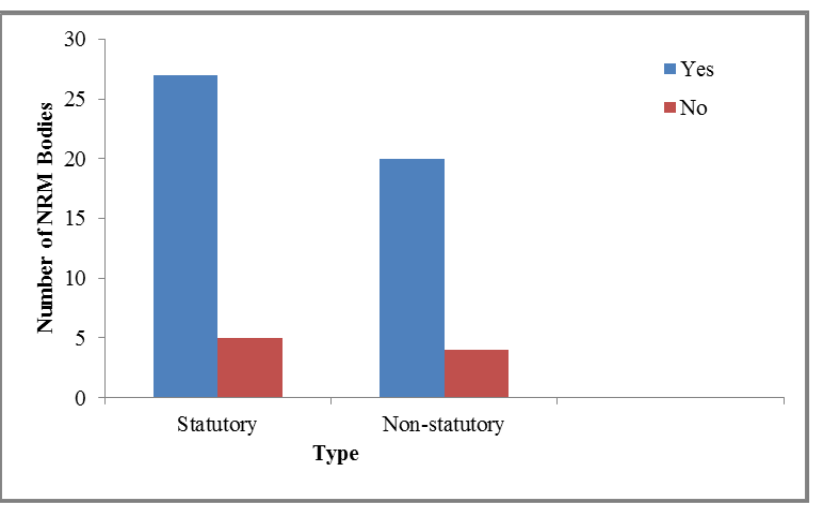

Figure 5: Collaborative arrangements

It was found that data sharing and spatial information management were the main areas of collaboration in both of the groups. However, there were some variations in the next most important area of collaboration. Statutory regional NRM bodies advised that the next most important area of collaboration related to technical skills and human resources sharing. The non-statutory regional NRM bodies advised that the next most important area of collaboration was knowledge transfer (Figure $6)$.

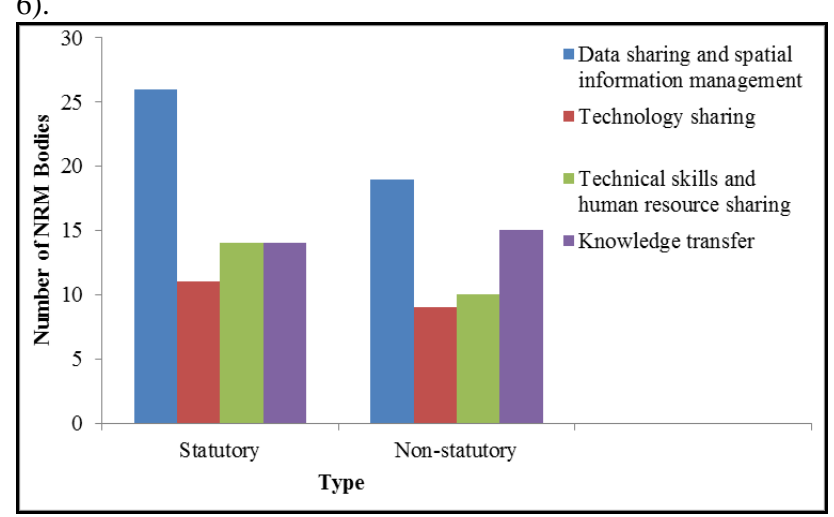

Figure 6: Area of collaboration
Again, this indicates that statutory organisations lack resources or the capacity for GIS activities and so collaborate in technical skills and human resources sharing. In the majority of statutory regional NRM bodies data sharing was undertaken through formal processes. However, in non-statutory groups, data sharing was done through both formal as well as informal processes. This indicates non-statutory regional NRM bodies are more dynamic and flexible in spatial information sharing.

\section{DISCUSSION AND CONCLUDING REMARKS}

The regional NRM bodies are not only spatial information users; they are also spatial information providers. The main users of spatial information generated or value-added by regional NRM bodies/CMAs are the community organisations like Landcare, Watercare, Birdwatch and land owners and indigenous groups. Government organisations, private sectors and academia/research institutions are less frequently utilising spatial information managed by regional NRM bodies/CMAs. However, there is significant interest in state government organisations to have access of community owned data. This has opened a new perspective on management of spatial information and development of spatial data infrastructure (SDI) in the natural resource management sector. Spatial information use, access and sharing have significance for SDI development in the catchment management sector.

It was found that there were subtle variations between statutory and non-statutory regional NRM bodies regarding spatial information access. Statutory regional NRM bodies operate more like government organisations. The most acceptable pricing arrangement for the statutory group was the cost of transferring data, and for the non-statutory group it was free access. Approximately half of the regional NRM bodies in both of the groups identified themselves as mature GIS organisations using spatial information for 5-10 years or more. The nonstatutory group was found to undertake more in-house GIS activities. Data sharing and spatial information management were the main areas of collaboration in both of the groups. The next most important area of collaboration for statutory regional NRM groups was technical skills and human resource sharing, and for non-statutory regional NRM bodies it was knowledge transfer. So, the non-statutory group appears to be more flexible and self-sufficient whilst statutory regional NRM bodies may lack flexibility in their spatial information management practices.

The results show the current statutory and administrative arrangements and regional focus for natural resource management is reasonable from a spatial information management perspective and provides an opportunity for building spatial data infrastructure at the catchment scale. However, effective institutional arrangements should align catchment SDI development activities with sub-national and national SDI development activities to address catchment management issues. We found minor differences in spatial information access, use and sharing due to varying institutional environment (statutory versus non-statutory). The non-statutory regional NRM bodies appear to be more flexible and selfsufficient whilst statutory regional NRM bodies are more dependent on government assistance and lack resources for spatial information management. From policy perspectives, the natural resource management at the regional scale is justified and effective. Within the regional delivery NRM model, there is opportunity for optimal spatial information collection, access 
and sharing and linking between policy initiatives and onground outcomes. It is also recognised that at the State/Territory level, the existing statutory frameworks affecting the spatial information management domain. The issue requires further investigation and some degree of statutory review and better coordination may be justified.

\section{REFERENCES}

Commonwealth of Australia (2000). Co-ordinating Catchment Management: Report of the Inquiry into Catchment Management. Canberra, House of Representatives Standing Committee on Environment and Heritage.

Davidson, J., M. Lockwood, A. Curtis, E. Stratford and R. Griffith (2007). NRM Governance in Australia: NRM Programs and Governance Structures, University of Tasmania, Australia.

Department of Environment and Resource Management (2011). Queensland Regional Natural Resource Management Framework, Regional NRM Policy, Department of Environment and Resource Management.

Griffith, R. (2009). NRM models and frameworks: Advantages and pitfalls, Natural Resouce Commission NSW.

HC Coombs Policy Forum (2011). NRM Literature Review: Document II, HC Coombs Policy Forum-Fenner School of Environment and Society NRM initiative, Australian National University.

Morrison, T. H. (2007). "Multiscalar Governance and Regional Environmental Management in Australia." Space and Polity 11(3): 227-241.

Pannell, D. J., A. Ridley, E. Seymour, P. Regan and G. Gale (2008). Regional Natural Resource Management Arrangements for Australian States: Structures, Legislation and Relationships to Government Agencies, SIF3 Working Paper 0809. CRC for Plant-Based Management of Dryland Salinity, Perth.

Paudyal, D. R., K. McDougall and A. Apan (2011). Spatial Data Infrastructure Convergence: Building Spatial Data Infrastructure Bridges to Address Climate Change. Geoinformatics for Climate Change Studies. P. K. Joshi and T. P. Singh. New Delhi, India, The Energy and Resourcecs Institute (TERI): 377-392.

Paudyal, D. R., K. McDougall and A. Apan (2012). "Exploring the Application of Volunteered Geographic Information to Catchment Management: A Survey Approach." ISPRS Ann. Photogramm. Remote Sens. Spatial Inf. Sci. I-4: 275-280.

Ryan, S., K. Broderick, Y. Sneddon and K. Andrews (2010). Australia's NRM Governance System: Foundations and Principles for Meeting Future Challenges. Australian Regional NRM Chairs,Canberra. 